\title{
On Mimesis (and Truth) in Performance
}

\section{Jon Erickson}

In the wake of poststructuralism and deconstruction, the notion of truth and its representation has come in for some hard times in the academic establishment. Due to a perception of Nietzsche as having reduced truth to an arbitrary metaphoric order imposed by human beings on the chaos of reality, as well as a reading of Saussure in which the relation between sign and referent is claimed to be arbitrary, the idea of referential truth becomes nothing but the specific efficacies of competing systems of discursive power. ${ }^{1}$ This way of thinking doesn't recognize its own performative contradiction: due to its conclusion of truth as arbitrary, it cannot claim for itself a truer depiction of what is than what it hopes to replace.

Both the analytical and continental traditions of philosophy involve engagements with how language represents reality. The major difference is that a large part of the continental tradition has more or less made up its mind in favor of the thesis I've just described, made more semantically fluid and uncertain by Derrida and materially imposed upon bodies by Foucault; this is taken as axiomatic by anyone working within its theoretical boundaries. Analytical philosophy, from Frege and Russell to Wittgenstein to Alfred Tarski and Donald Davidson, does not share this axiomatic confidence, and continues to ponder how truth works, how reference functions, how we make sense to one another and share meaning. ${ }^{2}$

Obviously there is an intimate relation between questions of truth and questions of representation, if only in the everyday sense of knowing what to believe when we hear, see, or read something, especially if it is information we need to act upon. But the question becomes more complex when we deal with literary fictions or theatrical performances; at that point the truth we seek or see there is not simply a matter of direct reference. And because what we read or see is a form of makebelieve, willingly entered into if understood as theatre, unknowingly if it is a confidence game, it elicits a level of concern about trusting or mistrusting what we are expected to accept as true in a general sense. ${ }^{3}$

In theories of the theatre, mimesis or imitation has always been a vexed issue because in the past the enemies of theatre confused the self-conscious use of mimetic illusion or make-believe with lying about reality (hence Sidney's response about the poet never affirming, therefore never lying). But within the world of the play, theatre artists themselves have shown how easy it is for some to use theatrical means to convey a false picture about what is the case-for Shakespeare the words "art"

Jon Erickson is Associate Professor of English at Ohio State University. 
and "seeming" are almost always suspicious signs of pernicious plotting-but also understanding that the same means can be used as tricks to reveal the falsehood of imposture (e.g., Hamlet and Measure for Measure). In more recent times, Brechtian metatheatre has been used as an anti-theatrical weapon against the theatrical illusion of naturalism, intending to reveal the uncritical workings of ideology. In a more aesthetic light, the anti-theatrical aspect of high modernist theatre is explored by Martin Puchner in Stage Fright: "Modernist drama and theater is a Platonist theater, by which I mean not a theater of abstract ideas but a theater infused with types of anti-theatricality first developed in Plato's closet dramas."4 Puchner's reference to Plato's "closet dramas" gives us a clue as to the real issue: Plato is understood by many to be anti-mimetic, but the irony is that his "closet dramas," his dialogues, are themselves mimetic productions, with Socrates as the main character. ${ }^{5}$

In this essay I argue that the notion of mimesis does not have to be automatically consigned to a Platonic idealism or theory of forms, and that Plato-or Socrates, rather-in the Republic is by no means consistently anti-mimetic. It is not simply mimesis in itself that troubles Socrates (though he notes its degraded state with regard to the ideal) but only particular uses of it, uses that should not trouble us in the same way, especially after Aristotle's revisions. Socrates wavers back and forth between wanting to condemn mimesis outright as eminently amenable to abuse and at the same time seeing it as inevitable and necessary for the education of his guardians. In the end it is not mimesis per se that bothers him, but inappropriate uses with regard to his utopian (and decidedly masculinist and stoic) aims.

Contemporary attempts to undermine mimesis as something substantial and pernicious in and of itself go overboard in their theorization of the term; in reality such complicated attempts are unnecessary for their specific critical purposes. Especially in deconstructionist readings of Plato's use of the word mimesis, a confusion occurs when mimesis is supposed to be understood, since Plato's time, as either inherently truthful or inherently idealist or theological, and as such needs to be shown as metaphysical and a form of false consciousness. This mistakes the possible truthful or false use of mimesis (which in itself is neutral) for mimesis as something true or false in itself. Clearly the representation of truth depends on the operation of mimesis, but the operation of mimesis need not be truthful; it can advance falsehoods as well, as Socrates knew.

To begin to show how this problem of confronting the idea of mimesis is read as an ineluctably Platonic one, to show how it is supposed to subtend the worst features of exclusionary social and political practices in the West and, beyond that, to show how the category of truth is also undermined by the apparent subversion of this Platonic idea of mimesis, I will examine Elin Diamond's theory of mimesis in her book Unmaking Mimesis. Her model for "unmaking" is the mimétisme of Luce Irigaray, a feminist theorist whose mentor and major influence was Jacques Derrida. In Diamond's book, according to her purposes, Platonic mimesis is marked 
as either essentially phallic and masculinist ("saming") or essentially feminine, understood as fluid, shape-shifting nature, an inherent threat to Plato's ideal of the unity of self. She mistakes both Plato's criticism of "womanish" behavior by suffering male tragic heroes, and Aristotle's proscriptions against female tragic heroes, as demonstrating the essential way in which mimesis makes representations of women impossible. ${ }^{6}$ If that were true, Plato wouldn't be making this criticism, nor would Aristotle be proscribing female heroes, as she puts it. As Halliwell's translation of the Poetics, Chapter 15, says, "For it is possible to have a woman manly in character, but it is not appropriate for a woman to be so manly and clever."' Despite Aristotle, Sophocles's Antigone and Euripides's Medea speak against that proscription. ${ }^{8}$ Yet it is true that Irigaray claims that for a woman to speak in a male society "a direct feminine challenge to this condition means demanding to speak as a (masculine) 'subject,' that is, it means to postulate a relation to the intelligible that would maintain sexual indifference." This is both a gloss of Aristotle's "manly in character," and the way in which both Medea and Antigone are described by their anxious male counterparts once they enter the argumentative space of the polis. For Irigaray, mimétisme, or mimicry (its English translation), is marked by the attempt by women to mimic the feminine as defined by masculine perception in order not just to play with the image, but to show themselves as playing with it to indicate their own agency "elsewhere," undefined by patriarchy. Her concern is that the feminine remain, with whatever attendant pleasure is derived from it by the female mimic, while also evading the proscription that necessarily codes all speech as masculine. But this assumes that mimesis must be coded as masculine, instead of seeing it as a neutral process by which certain hegemonic cultural practices or uses of it deem it necessary to regulate its defining terms. If women speak up, they are decried as being "male," if tragic male heroes demonstrate emotional distress, they are labeled "womanish" (by Plato, in any case). Luckily there are numerous instances of theatrical mimesis over the centuries that have ignored these defining prescriptions. While these two characterizations reflect the sexism of a given society (and there are quite a few), neither designation is an essential feature of the operation of mimesis itself. At a certain point Diamond claims that mimesis is "impossibly double," in order to indicate that it is both "masculine" in the sense of unified, coherent, and universal, and "feminine" as shifting, multiple, "a destroyer of forms"; the former is seen as "mimesis" proper and the latter as the "mimicry" within it that threatens its coherence and power. ${ }^{10}$ What this does, however, is simply reify, at a more abstract level, the implacability of essential differences between masculine and feminine attributes as tied to male and female gender, and by attributing the latter-the feminine as mimicry-to women, reduces their agency to forms of negation, however playful and personally enjoyable. I would claim that mimesis and mimicry are practiced in various ways by both men and women, that they are both essentially neutral forms of representation, and the doubleness that 
Diamond sees in them is the confusion of mimesis itself with its ideological uses. Hers is an unnecessary and overly abstract theorization of effects that is unlikely to work exactly as intended or even understood by the uninitiated, and perhaps not even by those who are in on the theory. Theory wants to maintain the purity of the intent even if it cannot control the interpretation of the effect.

Diamond's idea is to reduce mimesis to the process of "saming": "mimesis patterns difference into sameness." She takes it further: "Let's look at a recent damning definition: "Mimesis . . posits a truthful relation between world and word, model and copy, nature and image[.] . . referent and sign in which potential difference is subsumed by sameness." one of his main concerns about Homer's use of mimesis is the telling of lies about the gods: he recognizes how mimesis can be used to spread falsehood (Republic Book II). In the course of her book she tries to "unmake" or "ruin" this ideal notion of "saming" through the use of Irigaray's mimétisme. ${ }^{12}$ She links Irigaray's technique with Brecht's estrangement, assuming that mimesis as it typically operates as saming is the the same thing as what she calls realism, and that mimétisme and estrangement undermine realism as such. In this way her avowed Brechtianism makes her unreasonably conflate realism and naturalism, not recognizing that Brecht considered himself a realist in opposition to naturalism. His realism depends upon points of reference with regard to the nature of actual oppression in the world, or his didactic drama would make no sense. Such a use of "realism" as a stalking horse is a tendentious tendency all too common in defenders of a purist political avant-garde. ${ }^{13}$

Diamond reduces all approaches to mimesis to her version of a Platonic model. While at various moments she is careful to note the distinctions between Aristotle and Plato for general purposes, she ignores that important difference and calls the whole thing "the classical model" of mimesis, thus aligning herself with a monolithic notion as presented by Irigaray and Derrida. As Stephen Halliwell has noted in his important book, The Aesthetics of Mimesis:

Failure to do justice to this dialectic [Platonic v. Aristotelian approaches] is the main weakness in Jacques Derrida's approach to the history of mimesis, an approach that construes that history as governed by a necessary commitment to the value of truth and which is almost entirely silent about the significance of Aristotle's non-Platonic understanding as a whole, but theories of mimesis are not, and need not be, tied to a uniform, let alone a uniformly Platonist, metaphysics.

He continues, 
Moreover, Derrida's critique of mimeticism is vulnerable to an objection that has been brought against his thinking more generally by Hilary Putnam, namely that it identifies a "Platonist" model of representation, which seems to require unsustainable conditions of philosophical truth, with representation tout court, and counts the difficulties of the former [representation] as grounds of challenging the validity of any concept of the latter [truth]. ${ }^{14}$

The attempted negation of the question of truth in representation because it is identified with Platonism becomes especially problematic for any theory, like Diamond's own, that purports to convince us, or politically convict us, regarding the effects and possibilities of historical events and acts. But a theory of mimicry or mimétisme must itself be conventionally mimetic - that is, not succumb to the very ironic destabilizing effect it seeks to describe - without falling into an infinite regress or incoherence. All philosophy concerned with the adequate functioning of representation-adequate to our needs and to understanding conditions that both form and resist our needs, or put another way, concerned with the value of truth-cannot be reduced to Platonism tout court. Mimesis is not one perfectly defined monolithic Western idea, and human beings who feel themselves oppressed by hegemonic representations are not reduced to the mere choice between Platonic idealism and a subversive mimicry of it. And yet when writing about the theatre, there is a grain of truth in the idea that the mimetic model cannot help but partake of a kind of ideal imagining that seems Platonic, and that is an inevitable result of poiesis, the art of making that Aristotle links to the mimesis of theatre, even if Aristotle's thinking is disencumbered of worries about proper correspondence with ideal forms. ${ }^{15}$ It is understood from the outset that while the theatre may evoke aspects of the real world, it is not that world, nor is it the perfect corresponding representation of that world. Theatre's very form-inevitably self-conscious as illusion, despite any suspension of disbelief for the sake of emotional engagement-cannot help but present an "ideal" image. ${ }^{16}$ This is the difference that seems Platonic and yet is not Platonic. By “ideal” I don't mean a perfect model in a theological or eternal sense, but rather as a form that has no exact material referent. The theatre, no matter how embodied, appears idealist in its form and seems to render everything it (re)presents as ideal, if only in the sense that it is removed from reality. This goes for the most studied docudrama as well. As Brecht says, without solving the problem, theatre "theatres it all down." 17 On the other hand, the hyper-reflexivity of a Brechtian theatricalism has the tendency to "theatre it all up." The latter tendency is not necessarily a sufficient answer or solution to the former.

If we consider the difference between Plato's ideal forms and Max Weber's "ideal types," we might be able to approach mimesis in the theatre a little differently. 
That is, in the first chapter of Economy and Society, Weber makes the important point that it is difficult, if not impossible, to define things in categories - and therefore effectively put to use such categories for our decisions - without assigning them a clear, delimited, and consistent identity across a variety of contexts. And we do this while knowing they do not match up perfectly with our expectations of them, and alter with circumstances as well. ${ }^{18}$ But, as in any science, the measure of something's truth-value is the measure of its predictability as it helps us define it as an ideal type. This pragmatic conception of the use of types is much closer to an empirically minded Aristotle, who referred to "kinds" of characters and actions, than to an idealist Plato. Thus, for instance, in the Poetics Aristotle counters Plato's negation of mimesis, as distorting the ideal truth of a thing's or person's self-same identity, with a conception of plausibility that relates to a kind of common social experience: types and kinds of human character and behavior that we already recognize within our social existence. The aesthetic and ethical criteria Aristotle sets up for both spectator response to character and action in the Poetics are, basically, ideal types in the Weberian sense for producing what he considers to be the most effective drama. There "representation" meets "production" halfway-which indicates one does not simply displace the other. Aristotle indicates that in drama there is no mimesis without poiesis, that is, an act that is creative, a making. ${ }^{19}$ Aristotle's distinction between history and poetry attempts to clarify the mimetic problem insofar as history is supposed to reveal what is, poetry what could be (although it is obvious to us today that history involves a rhetorical "making" as well). Further, the fact that dramatic mimesis is made-partakes of poiesis-already indicates its artifactuality, not its pretension to being a simple mirror of reality. As noted elsewhere by Aristotle, art (techne) doesn't mirror nature, it "completes" it. The poet does not simply copy but creates through using resemblances of what is, i.e., is familiar or understandable. But this creation is at the same time an interpretation, as Gadamer would have it, or as he puts it in Truth and Method, a "highlighting.""20

Performance in the theatre, no matter how embodied, is still transcendent, if only through the slippages and diverse possibilities of signification and meaning and the variable nature of attention and focus. In this I may seem to be affirming a kind of deconstructive metaphysics, but I recognize the theatrical, in its production of a possible (other) world, for what it tends to manifest itself as - a linguistic (or semiotic) idealism. It is this which prevents a truly "materialist" theatre from ever being possible. Even ruthlessly self-deconstructing theatres, such as the Wooster Group, develop an aura around the nature of their deconstructions. The "real" standpoint from which they undermine their own processes becomes idealized as the fulcrum of all attention paid to the nature of attention. None of what I say here is negated by the material, kinesthetic experience of theatre as a present and physical medium. That indeed is the stratum it is built upon, but it is also never simply that. Theatre's transcendence is encountered within this very experience 
that draws us out of our habitual mindsets and moves us emotionally through the meanings evoked by the language of its speech, gestures, images, and forms.

Years ago I discovered in the process of playing with my baby daughter, that is, when I made the faces she was making back at her, or when I made sounds that she made back again to me, that I sometimes encountered a problem of interpretation. That is, I believed that I was engaging in simple mimesis, mimicking her sounds, so that it would encourage her to make more, and it would seem as if we are actually engaged in a kind of conversation. But I also noticed that at certain points, I felt as if she might be experiencing my mimicry as mockery, and was not always clear when it appeared to her I had crossed a line. It was most clear, obviously, when she was making angry or upset sounds - mimicking them would incite her even more (thus taking it as mockery). But even when she was making happy sounds, the insistence with which I made those sounds back to her, especially if it seemed to swamp her own efforts, was perhaps taken as something aggressive. Where and when and how does one draw the line between simple mimicry and mockery? What is it in the context of reception that causes this to happen? If this is the case, there can be no perfect intentional control over this interpretation.

The transition from mimicry to mockery as I encountered it with my daughter seems marked by a sudden disconnect, a shift from an apparent action with to an apparent action toward her, an awareness of a forceful use of an expression instead of an immediate experience of the expression itself. Obviously a child this age would not make this use-content distinction at the sophisticated level an older child would. Nonetheless a cognizance of a kind of force behind the expression becomes known and is a matter of alienation and concern for her. This happened despite any intention on my part to use mimicry as an alienating force.

Does this also portend a transition to the "fictive," a metatheatrical marking? We do, after all, understand mockery to be a highly self-referential form of mimesis, practically seeing the quote marks around its expressions. Scare quotes indeed: that mark off, through an exaggerated foregrounding of the particular that suddenly becomes a disconnected abstraction, an aggressive use that is at the same time a disavowal of, or rejection of concern for, its possible truth-value. (At an older age children frequently engage in the annoying game of repeating back to other children everything they say, just to watch them react in frustration.) The strategy aggressively turns the sincere expression of the other into an empty and impotent mask. But oddly enough it is precisely the use of such mockery, or perhaps overuse, that can also uncover the emptiness and impotence of the mocker, the lack of any other discursive means to resist or make one's case. This is the case, whether found in more naïve forms of resistant performance or in theoretical writing. The more scare quotes one finds in an article, for instance, the less likely one is to find an actual argument adequate to its purported critical aims. The article may be only preaching to the choir, as opposed to an attempt to convince others not already in 
the writer's circle.

My point is that the fictive element in this transition from shared mimicry to (a sense of) an imposed mockery can bring with it a realization of rhetorical means revealing certain intentions not recognized before this point. Does this mean that rhetoric connotes fiction (in other words, don't take me at my word)? Here we have to be on our guard, because we might then think that any means by which we communicate a truth is "in itself" not truthful and hence likely to vitiate the truth it is supposed to convey. Hayden White contends that fiction and history are one in this sense-the rhetorical means for the articulation of each are exactly the same. And there is much to commend in this position. But if meaning is use, according to Wittgenstein (and the recognition of the distinction between mimicry and mockery is precisely this), then a distinction should arise between means and meaning. For use is not means alone, but the intention and its framework, which motivates particular means in a particular direction, which we then argue as the truth of a situation.

When Diamond eventually claims that there is a truth to be conveyed in performance, it is essentially the contingency of one's historical position. ${ }^{21}$ One's historical truth is always already interpreted from one's own historical position, which is highly unstable and requires an assertion of one's own self-production of identity as a basis. This gives rise to the historicist paradox in which the truth of any other historical moment is contingent on one's interpretation arising from one's own historical moment, which is also contingent, and the flow of temporality continually challenges that truth. It's like trying to shoot from one moving train at a target on another. So with all this contingency moving around-another name for chance or circumstance-whatever truth there may be is largely indeterminate, and one claim could be as good as another. If that's the case, the very notion of truth becomes suspect. What's more, we can wonder to what degree theatre can ever really function as a conveyer of historical knowledge, which is a requirement for understanding how history works in the first place. Indeed there is some truth to this as a perpetual problem for theatre, perhaps more than for written narrative. Does Brecht's idea that the audience will see itself historically by seeing the events on stage historically ever really work? Or does it simply flatter our (or his) more perspicuous historical position, while assuming that our critical recognition of the falsehoods of past social belief is going to automatically lead to understanding the falsehoods of our own? ${ }^{22}$ But then again, the problem of confirming historical truth and falsehood seems of little interest to Diamond. For her, historicization is supposed to succeed in unmasking the uncertainty and implausibility at the heart of the patriarchal mimetic model of truth without proclaiming its own truth (at best maybe its own desire). Diamond characterizes the situation this way: "Brechtian historicization assumes and promotes both unofficial histories and unofficial historians . . . a move that produces not 'truth,' but mastery and pleasure." ${ }^{23} \mathrm{Am}$ 
I alone in finding this truthless "mastery and pleasure" politically disconcerting?

There are implicit truth-models involved in any interpretation or reception of theatre. This is true even with those theories influenced by poststructuralism that are anti-mimetic or claim that truth is merely an effect of structures of power, that it is "made" and not discovered; this is the "performative," as opposed to the "theatrical," view. In this case the presumption of truth beyond mere making is found in the claim that truth is merely "made." This fundamentally romantic model is that of a demiurge - itself Neo-Platonic — whether attributed to human beings or their institutions. There is a prevalent idea that theatre works from no models, and that it creates its own models. But this is erroneous: it works not from ideal forms, but from living types, as Aristotle knew. Even if it didn't, no actor would be able to perform a completely unrecognizable figure, nor would any audience member have the possibility of even recognizing it, much less identify with it. Degrees of abstraction from possible models, however recombinant they may be, should not lead us to assume they are only products of the stage sui generis or ex nihilo.

The problem with the poststructuralist critique of mimesis is the typical deconstructive projection of an all-or-nothing definition onto what it is purporting to critique, even when the authors who are the objects of the critique never claim such. Mimesis thus is said to reduce all difference to sameness, to perfect identity. No one has ever made such a claim, not even Plato. In Book 10 of The Republic, we recall, Socrates's remark about the painter's rendition of the bed shows it falls short of the reality of the ideal bed, much less the constructed bed, and always will. That for Plato is one of the problems with mimesis: it is not, nor can be, faithful to the ideal original — not that it renders reality so perfectly that we are confused by it. For example, one might counter this by saying that the other problem for Plato is that of the spectator mimicking what become models of behavior seen on stage through confusing artifice with reality. But the assumption of bad habits through imitation of bad characters is not necessarily the result of cognitively confusing the representation for the reality. This is qualified for adults when Socrates notes that children are incapable of understanding what they see or hear "allegorically,"24 but even the literal need not be confused with the actual. One might realize that an act of physical cruelty by an actor is faked, and at the same time be unconsciously inspired enough by the context of its intentions to mimic the behavior. What he would claim is that the mimetic power that appeals to the baser emotions tends to bypass the higher power of reason in the soul. Socrates comments about the skill that Homer demonstrates in this facility for inducing pleasure, and it is precisely because of this skill-which even he admires-that it is so dangerous. But again, it is a particular use of mimesis — whatever the actual validity of Plato's claims about the use may be-not mimesis itself.

Mimesis as the reflection of the ideal becomes in poststructural constructivist reasoning simply a reflection of class interest and hegemonic meanings. But its 
operations in different ideological settings remain the same functionally, even if its object is different. Diamond's use of mimétisme as "mimesis with a difference" presupposes that there can be mimesis without a difference, hence the need for mimétisme. But, in fact, if one denies the perfect functioning of mimesis as a concept, wouldn't one have to say that all attempts at mimesis result in mimétisme? Not as intentional distortion (or should I say interpretive refashioning?) for personal ends, but as a continual falling short due to the inevitability of not being able to wholly determine one's ends. Mimétisme becomes the display of pointing to the inevitable inability to be fully mimetic as something intentional, or as Judith Butler might put it, adventitiously "working the weakness" of the inevitable failure of iterative stability in what is articulated. The reverse can be the case too, as when, in Waiting for Godot, Pozzo after his oration admits to have faltered at the end, while Gogo thought it was "intentional." The same issue may exist with regard to the apparent intentionality of what is called "strategic essentialism."

The curious thing about responses to Plato is the way in which deconstructive critics who are purportedly anti-Platonic seem to believe in the truth of what he says, while being opposed to his attitudes about its value. ${ }^{25}$ Walter Kaufmann believed that Brecht, for instance, was a Platonist. ${ }^{26}$ This seems highly unlikely since Brecht claimed to be a materialist and Plato was an idealist. Yet it is more likely that "the enemy of my enemy is my friend." That is, since Aristotle is Brecht's enemy and Aristotle revised Plato's views on mimesis and the passions in the theatre, Plato is now Brecht's friend. Aristotle's view of theatre is a relatively benign one. His ideas about catharsis seem to answer Plato's concern about the arousal of irrational emotion in a rational Republic and the mimetic subversions of models of the good by presenting models of vice. Brecht, in wanting to see theatre as a revolutionary force, has to find a way of overcoming Aristotle's sanguine theory of "repressive desublimation," to borrow from Marcuse, ${ }^{27}$ and finds an ally in the disruptive view of theatre of Plato. Brecht's subversive nature delights in what Plato feared, but in the process he affirms the supposed truth of Plato's view. One often finds theatre scholars actively seeking out anti-theatricalism in others as a way of proving just how potent and anxiety-producing theatre is, when in fact it is unlikely that theatre today has much potential for such. The repeated assertions that J. L. Austin is "antitheatrical" because of what he said about the lack of the appropriate social or legal conditions for the felicity of certain speech acts like marriage vows on stage is a telling and overwrought case in point. ${ }^{28}$

In like manner, Diamond, influenced by deconstruction, opposes Plato because of the assumption that his notion of mimesis corresponds to an ideal or divine model of truth, which to her mind promotes the conception of an eternal fixity of nature. Given the patriarchal context, this means that women will never be able to alter their condition as long as that mimetic model is fixed. And so it must be 
subverted. But is she, and the artists she represents, subverting that model of mimesis (mimesis "itself"), or do they believe they are in specific instances subverting the particular applications of that model of mimesis? Diamond seems to take Plato at his word about the relation of mimesis to ideal forms, instead of simply saying: his notion of mimesis is wrong, it is not like that at all. If she thought his notion of mimesis didn't work, there would be no point in trying to subvert it. She thus seems to believe in his notion of how mimesis works, even if she doesn't like how it works. But in fact Aristotle messes that up. His idea that mimesis is also articulated through an individual creative mode called poiesis - that it is never just replication of a pre-existing ideal but something made by an individual with an individual's vision - already articulates the inevitable difference that always already inhabits mimesis. There is no "saming." Perhaps mimétisme is just another version and use of Aristotelian mimesis-plus-poeisis without knowing it.

What's more, even though Diamond at one point refers to Homi Bhabha, Bhabha also undermines the "saming" thesis that animates racist colonialist discourse as much as it does sexist discourse. For him, the imposed mimesis on the colonized in India by the British is not a question of "saming," of turning the colonized into clones of proper Englishmen (nor certainly the opposite: reading them as savage "others" merely), but of rendering them the "same but not quite," so as to justify their ongoing colonization as a "civilizing" mission. (But even here the problem is assuming that difference is simply an issue of intention rather than inevitable result). ${ }^{29}$ Seen from the opposite perspective, those who fear the globalization of American culture as homogenizing - that is, turning everyone into American clones - can't see the difference that inevitably comes from the creative (poiesis) "indigenizing" effects in the mimesis of Western models, which in fact rebound back upon the Western model and alter it as well. ${ }^{30}$ One could take this farther and ask what in this process remains essentially "Western." There is no simple either/or way of conceiving of mimetic processes.

When we consider the nature of the theatre, and the appreciation one brings to it in admiring the effects of actors on our consciousness and emotions, it is because we accept, as it were, two realities at once (or almost at once) - and the quality of their interaction to evoke truths that we find compelling if not necessary. That is, one reality is that of the actor and her skill; the second reality is the drama itself, which the actor through her skill brings to life; and out of the most skilled and fortuitous interactions of these realities arise truth and meaning about our condition as we perceive it as being or could be. It is not necessary, as is often thought, for the actor's reality to disappear entirely into that of the drama for the performance to have this effect on us. Our admiration for the actor then would cease, and our understanding of any truth we might receive would be distorted in its partiality. Our admiration for the actor's skill in bringing the fictional reality to life will not necessarily dispel any larger (psychological, political) truth that is conveyed by 
the performance. Yet the question remains whether one can actually hold both realities - the theatrical and dramatic - in one's mind at the same time, or if it is not an effect of switching, as is the case when we view a figure/ground conundrum (duck/rabbit, two profiles/one vase). We are caught up in the imaginary of the drama and momentarily forget the theatre, even as we are brought back to the theatrical level in the appreciation of the skill of the actor. ${ }^{31}$

All of this seems limited to the theatre. But is it? When we read theories of social construction, we are continually encountering the formation of one half of a binary that wishes to overcome its complementary other while never escaping it entirely. I am thinking of the endless social construction/essentialism antagonism. The terms as we encounter them in deconstructive theatrical theories could then be implicitly equated as: theatricality $=$ constructionism, drama $=$ essentialism. In other words, we read it in the terms of antirealist avant-garde apologists who view dramatic realism as the ideological mystagoguery of essentialism. But yet, what attempt at a wholly theatrical form of performance is truly possible? Any more than a wholly social constructionist view of reality that never for a moment slips unconsciously into essentialist thinking? To reverse matters, how do we know that the theatrical alienation effect would have any more authority than the dramatic situation it is framing? Could one read it in reverse? The dramatic situation is framing the gestus, and this is the only way people can make sense of the alienating signifier. The attempted elimination of acting or roles appears to many as the easiest way of eliminating realism entirely from the scene and instituting skeptical theatricalism. And yet can one have theatricality without roles? Such things always return in the mystification of the performer himself as skilled - rhetorically, physically, dialectically, and so forth. Thus the late Spalding Gray in a highly accomplished way mystified in the very act of self-revelation. His "performed authenticity" should not be understood with the stress only on the first term, but in its conflicted and ambiguous relation to the second, which is just as important. And it is this effect of authenticity on the spectator, even as the mechanisms of the performance's creations are being pointed out, that accounts for the ineradicable dramatistic or essentialist component.

In other words, radical social constructionism wants to be the only moment of mastery, a kind of omniscient, canny sense that believes it can create without any essentialist blindness. But this is impossible, demonstrated by the contradiction we see in Nietzsche's essay "On Truth and Lying in an Extramoral Sense," where he wants to claim that truth is always only an effect created by dead metaphor, but that means that his own truth about this truth-making calls into question the actual nature of his claim: either an infinite regress or self-contradiction. ${ }^{32}$ Foucault tried to make this point more forcefully through his socialization of the issue as "regimes of truth" but was no more successful than Nietzsche in avoiding contradiction. Much the same thing can be made of a variation on this "truth-production" theme: 
the new ideal of the performative. But the performative-however Derrida and Butler read Austin - as a form of construction depends upon a taken-for-granted "essentialist" belief in a constative structure that upholds and empowers it in the first place. To claim that every constative is always already a socially instituted performative with no more perspicuous or perduring truth-value than any dependent performative itself is to engage in the same kind of infinite regress as Nietzsche's founding of truth in the creation of metaphors. ${ }^{33}$

While it is easy to imagine that the drama we see unfold as an imaginatively believable fiction is entirely dependent upon a theatrical or socially constructed basis, it is perhaps less easy to recognize that the self-conscious aspect of theatricality itself depends upon an unquestioned basis in a belief in the power of theatricality to create this dramatic fiction. In a sense this simply pushes the frame of the psychic proscenium but one step back (note what was said above about the Wooster Group). Again, this is similar to the problem that, in order to believe Nietzsche's concept of truth-production, one has to put into abeyance Nietzsche's own truth production and accept it as "true" beyond mere "production" on Nietzsche's part. The suspension of disbelief regarding Nietzsche's performative contradiction that exempts his truth claim from mere metaphorical production-his claim about such production is true - oddly reflects the very ontological condition of theatre, where it is difficult, if not impossible to separate the phenomenological from the ontological. ${ }^{34}$ It is the "essential" nature of construction that is both accepted and forgotten at once.

What may be most disturbing about mimesis is less when it is gotten wrong than when it is gotten right. Either we don't want to admit the truth of what we're seeing, or else we feel a loss when what we see is the thing we've wanted to keep private and solely in our possession. If the play is the thing to catch the conscience of the king, what is its purpose for the rest of us? When it comes to performance with a political intent, for instance, it seems to orient itself to implicate each of us within a web of complicity with social forces to which we ought consciously to give assent to dissent; it wants to position us for the sake of blame or critical empowerment, or both. It seems designed to show us what we are and/or what we should be. This requires, at the very least, a process of recognition. But can we recognize ourselves in it?

While above I distinguished mimesis from mere mirroring, I want to revisit the mirror once more as a metaphor for mimesis, and see if there isn't a difference to be found in the process of mirroring itself. What is it about the mirror that can sometimes prove so disconcerting to us at certain moments? When we see ourselves age almost overnight? When we wonder if this person is what others are seeing? While I admit that there is a problem with seeing mimesis quite simply as a "mirror" (Plato's little joke about the easiest way to represent something, whose simplicity as a concept is defeated by Aristotle's complication by poiesis), there is also Hamlet's more serious take on showing the world (and the king) its own face. 
Mirrors obviously do not "mimic" anything: they reflect, but for Hamlet to act is to imitate the mirror in its power of reflecting social reality as it is. Even Brecht's aim is nothing more than this. But it does not-or cannot-do so directly. Brecht found that it worked better for the sake of critical audience reflection to place current social conflicts in the contexts of other historical moments, just as for the tragic theatre of Athens the cities of Thebes and Corinth conveniently served as Athens's "evil twins" as an indirect means to otherwise painful self-criticism. Jean-Paul Sartre has noted that we cannot see ourselves in the mirror as objects - that is, objectively-for we are always already seen as accepted images that inure us to any actual recognition, especially as to how we appear to others. ${ }^{35}$ But even Sartre admits that mirrors can provide a fleeting shock of objectification at the right moment. It is then that the split in representation presents itself, in which the shock of recognition transpires precisely because of an almost simultaneous lack of recognition.

In recent cognitive neuroscience studies, something called "mirror neurons" found in the forebrains of monkeys have been hypothesized as having an immediate effect in human beings who unconsciously imitate the gestures and attitudes of others in their presence. ${ }^{36}$ In both the theatre and dance worlds this has been referred to as "kinesthetic" response. The unreflective immediacy of this impact - called "simulation theory" in philosophy of mind - in contrast to "theory theory," which requires cognitive introspection before engaged empathetic response-no doubt inspired Plato's concerns about the contagion of behavior spreading from the stage to the audience. In fact, most theorists engaged in this debate accept a hybrid version of the two theories, with some leaning more to one side than the other, but both recognize the initiating effects of simulation. ${ }^{37}$ It is also found in Aristotle's distinction, in Chapter 14 of the Poetics, between the immediate, kinesthetically mimetic effects of theatrical spectacle on audience emotion, which he downgrades to the merely "sensational," as opposed to the deeper emotion of fear that is properly an effect of understanding the trajectory of the plot. ${ }^{38}$ This simulative mirroring process forms the condition of possibility for recognition, but it requires something more (according to Aristotle, something discursive) to trigger a power inducing a deeper emotional self-awareness.

I always find myself returning to Freud in the railway carriage, mistaking his reflection for that of another old man, and then realizing it is he himself. What he then called "the uncanny" is not the original perception of the strange old man, but the frisson between that stranger and the person Freud knew himself to be, between what Sartre called the object and the image. As Paul Ricoeur referred to it in a very different context, it is "oneself as another." ${ }^{39}$ The problem as it exists for spectatorial self-reflection based on a mimetic relation to stage actions has to do with overcoming one's habitual self-image in order to see oneself as others might see one. 
None of what I have said about what I think are Diamond's mistaken assumptions about mimesis should be taken to disparage the importance of her aims to see that women critically confront the way their social and cultural representations have served historically to diminish, marginalize, or oppress them, or to see that dramatic means be found to reverse this tendency and empower women in their various means of self-representation. In fact, her approach in Unmaking Mimesis to how this is done, from the plays of Aphra Behn, to Elizabeth Robins's performances of Ibsen, to East Village lesbian performance, can constitute strategies for confronting this issue and triggering recognition. But the specific theoretical way she founds these strategies in an essentialization and presumed subversion of the Platonic as the universally accepted definition of mimesis is mistaken. There is no question that specific, oppressive kinds of representation can be altered and turned back upon themselves; that, as she so ably demonstrates in her chapter on Ibsen, even the historical moment of depicting middle class women as "hysterical" can be rewritten or replayed so as to turn the apparently symptomatic to real critical advantage in a political sense. But, as I've said, all of these are specific uses of mimesis that serve a different intent and aim than the socially hegemonic uses put to them. Hopefully, different understandings that challenge such historically dominant uses can also be accomplished by mimetic means, rather than attempting a futile undermining of mimesis itself as some essential category of the determination of being. And it is precisely because mimesis eludes anyone's complete control, even in terms of self-representation, that its variety of uses, socially critical but also self-revealing or self-illuminating, are possible.

The point behind both the story of the miming game with my infant daughter and the sometimes uncanny nature in which mirrors reflect back what we don't quite recognize, or are afraid to recognize, is that mimesis, no matter with what exactitude we prepare it for the sake of a specific communicative or demonstrative aim can always provoke a quite different interpretation than what we expect or desire. However satisfied we may be about how we theorize our intentions, it won't guarantee the expected reception. This forms part of the learning process for the theatrical artist as much as it does for the audience. Diamond is right to pay attention to Plato's anxiety about the lack of control over what he thinks are its proper uses and modes of reception - which are clearly sexist in nature. But her assumptions about the "saming" power of mimesis itself and her confident belief that mimétisme can itself be adequately controlled to undermine this power and establish its own form of proper reception belies that very understanding of the lability of mimesis as it is. In fact, the more complex the intended reception, the less likely one will be satisfied with what actually occurs. ${ }^{40}$ With mimesis (plus poeisis) our desires can be given free rein, but we can only do the best we can with what is available to us. Any measure of communicative success requires a measure of credibility, of plausibility — about both present conditions and any possible alternatives - for 
the aims of audience recognition and acceptance of the believability of the staged scenario, before any critical work can be accomplished. And we should leave open the possibility that the result might be something quite different than we expected it to be. Such are the risks and value of mimesis in its variety of uses.

\section{Notes}

1. For a critique of Derrida's misreading of Saussure, see Raymond Tallis, Not Saussure: A Critique of Post-Saussurean Literary Theory (New York: St. Martin's P, 1995). Tallis points out that for Saussure, arbitrariness exists between signifier and signified in the makeup of the sign, not between the sign and its referent.

2. This doesn't mean there aren't occasional parallels between the two traditions-Richard Rorty's pragmatic consensualist theory of truth, for instance.

3. For an insightful reading of the fictional framework of theater, see David Saltz, "Infiction and Outfiction: The Role of Fiction in Theatrical Performance" in Staging Philosophy: Intersections of Theater, Performance and Philosophy (Ann Arbor: U of Michigan P, 2006). Saltz provides a critical elaboration of Kendall Walton's important theory of mimesis found in his Mimesis As Make-Believe (Cambridge, MA: Harvard U P, 1990).

4. Martin Puchner, Stage Fright: Modernism, Anti-Theatricality, and Drama (Baltimore: Johns Hopkins U P, 2002). Puchner's identification of modernist anti-theatricality with Plato's seems to be focused on the inherent failure of human actors to represent the ideal sought after in modern formalism. But in indicating this he does not deny the fact that acting itself is ineluctably mimetic.

5. A fine example of Socrates himself playing the role of another appears when he speaks in the voice of the deceased Protagoras in the Theaetetus. This contradicts Socrates' own criticism of Homer, in Republic Book III, for speaking not in his own voice but in that of a character. 1997) vi.

6. Elin Diamond, Unmaking Mimesis: Essays on Feminism and Theatre (New York: Routledge,

7. The Poetics of Aristotle, trans. Stephen Halliwell (Chapel Hill: U of North Carolina P,1987) 47.

8. What complicates the matter even more is that Socrates includes women in the class of guardians, and indicates their general equality to men in capability (even in war!) with the only difference being that of relative physical strength. See Republic Book V: 455e and 457b.

9. Luce Irigaray, This Sex Which Is Not One, trans. Catherine Porter with Carolyn Burke (Ithaca Cornell U P, 1985) 76.

10. Diamond, $v$.

11. Diamond, iii. She is in fact citing herself, from her earlier essay "Mimesis, Mimicry, and the True-Real," Modern Drama 32 (1989): 58-72. (Unmasking Mimesis, 182).

12. Diamond comments, citing Irigaray: "[T]o recover the place of her exploitation by discourse, without [being] simply reduced to it" is to display a nonidentical similarity to the other, whereas patriarchal culture sees only "the one of form"" (174). See my later comments on "saming"; "nonidentical similarity" strikes me as a pleonasm, but it nonetheless more accurately describes basic mimesis better than "saming," since a word or action cannot be at the same time the thing it represents. A large question is how an audience member is to understand the complexity of this theoretical intention enough to distinguish it from parody or mockery.

13. Lest I appear "anti-avant-garde" in this, which I have never been, I once gave a lecture called "Avant-Garde or Realism: Must We Choose?" The answer for me is no. See also Toril Moi's criticism of Diamond's attitude toward realism in "Ibsen, Theatre and the Ideology of Modernism," Theatre Survey 45.2 (November 2004) 248.

14. Stephen Halliwell, The Aesthetics of Mimesis: Ancient Texts and Modern Problems (Princeton, NJ: Princeton U P, 2002) 374, 376.

15. Diamond attempts to elide the Platonic-Aristotle distinction by making it seem as if what she calls Aristotle's "universals" are the same thing as Plato's forms (xii).

16. Bruce McConachie disagrees with Coleridge's formulation of "the willing suspension of disbelief," utilizing a cognitive theory called "cognitive blending," which he claims works unconsciously in the spectator, who "oscillates" in and out of attention to the fictional state of the play and the stage reality producing it. This, he claims, defeats Coleridge's idea that suspension of disbelief is a willed activity, in which "willing" means "conscious effort." However, at one point he equivocates, with no 
other way of dismissing Coleridge's point than putting "willing" in scare quotes: "Some 'willing' may occur at the start of a performance and intermittently throughout, but it is clear that spectators do not need to make conscious decisions about blending and unblending" (559). In Coleridge's advice to the reader about accepting the fiction of his supernatural poems, it is clear that it is the initial contact with the subject matter he is talking about, hoping of course that the power of that fiction will carry the reader along, indeed unconsciously, after that. So too McConachie admits that the start of any performance requires an adjustment on the part of the spectator to the fiction. I have yet to see a performance in which I haven't experienced the first lines spoken as that of a dramatic text being presented to me, before I can enter into the world of the play itself. I would claim that giving myself over to the play is a form of letting go, which can obviously be pleasurable; "letting go" seems contrary to "willing," but not if one takes Coleridge's whole phrase into account, which then makes it more or less synonymous with letting go. I agree that, once underway, McConachie's point about blending - moving in and out of the fiction unconsciously-makes sense, and "willing" is less of an issue. But this presumes a kind of optimum performance; what if either the play or the acting is terrible? In those cases, attempting to maintain some kind of absorptive relation to the make-believe world of the play seems to require a form of active willing. A lot depends on how one perceives the relation between conscious and unconscious processes and where and how you see one or the other in control.

What's more, McConachie attempts to distinguish between "illusion" and "make-believe" (566), which seems to me in ordinary theatrical terms to be a distinction without a difference. See McConachie, "Falsifiable Theories for Theatre and Performance Studies" in the Performance and Cognition issue of Theatre Journal 59.4 (December 2007) 553-78.

17. From "The Literarization of the Theatre," Brecht on Theatre, ed. John Willett. (New York: Hill and Wang, 1964) 43.

18. Max Weber, Economy and Society Vol.1, ed. Guenther Roth and Claus Wittich (Berkeley: U of California P, 1978) 6-7.

19. To be fair, Diamond approaches this differentiating productive side to Aristotle without using the term poiesis.

20. Hans-Georg Gadamer, Truth and Method $2^{\text {nd }}$ edition, trans. Joel Weinsheimer and Donald G. Marshall (New York: Continuum, 1996) 386, 400.

21. Diamond, Unmaking Mimesis 49-50.

22. If we read Brecht's use of historical distancing as a framework for a parable relevant to our own time, then this question of historicizing ourselves isn't really applicable.

23. Diamond, Unmaking Mimesis 50.

24. Plato, The Republic, Book II: 37-8e, trans. Paul Shorey. The Collected Dialogues of Plato, ed. Edith Hamilton and Huntington Cairns. (Princeton, NJ: Princeton U P, 1985) 625.

25. In this regard many classicists, doing in-depth analysis of the context in which The Republic was constructed as dialogue, note that the concept of mimesis is not something set in stone by Plato, but is used rather flexibly in the course of conversation, that there are contradictions in Socrates' claims for it, and that Socrates didn't simply dismiss it because it was necessary in order to educate the Guardians the right way. In this sense, The Republic should not be read as the perfected theory of either justice or representation, but in many ways a rather inadequate active hypothesizing on the spur of the moment, while nonetheless raising questions that have remained perennial ones for society. An excellent source for seeing the difficulties with viewing the Republic as a coherent treatise is Julia Annas, An Introduction to Plato's Republic (Oxford: Clarendon P, 1981). Regarding Plato's idealism, see also Drew A. Hyland, "Against a Platonic 'Theory' of Forms," Plato's Forms: Varieties of Interpretation, ed. William A. Welton (Lanham, MD: Lexington, 2002).

26. Tragedy and Philosophy (Garden City, NY: Doubleday, 1968).

27. See "Repressive Tolerance," A Critique of Pure Tolerance, Robert Paul Wolff, Barrington Moore, Jr., and Herbert Marcuse (Boston: Beacon P, 1969).

28. See Introduction, Performativity and Performance, ed. Andrew Parker and Eve Kosofsky Sedgwick, (New York: Routledge, 1995); Judith Butler, "Critically Queer," Bodies That Matter (New York: Routledge, 1993). See also Martha Nussbaum's response to this claim in "The Professor of Parody," The New Republic Feb. 22, 1999.

29. Homi Bhabha, "Of Mimicry and Man: The Ambivalence of Colonial Discourse," The Location of Culture (New York: Routledge, 1994) 85-92.

30. One could claim that the growing economic power of Asia and its slackening in the West may problematize these distinctions even more. For an anthropologist's view of the "indigenization" of facets of Western culture in fourth world contexts, see Marshall Sahlins, "What is Anthropological Enlightenment? Some Lessons of the Twentieth Century," Culture in Practice: Selected Essays (Cambridge, MA: Zone Books, 2000). 
31. I am happy to see that McConachie's claim about cognitive blending with regard to stage reality and the fictive reality of the drama supports this point.

32. "On Truth and Lying in an Extramoral Sense," Philosophy and Truth: Selections from Nietzsche's Notebooks of the Early 1870's. trans. and ed. Daniel Breazeale (Atlantic Highlands, NJ: Humanities P, 1979). For an argument against the idea that this essay exemplifies Nietzsche's general attitude toward truth, see Maudmarie Clark, Nietzsche On Truth and Philosophy (Cambridge: Cambridge U P, 1990).

33. In his reading of Derrida's take on Austin, Stanley Cavell, a student of Austin's, makes it clear that Derrida cannot turn Austin into a Nietzschean after the fact, making it seem that Austin replaces truth with force. See A Pitch of Philosophy: Autobiographical Exercises (Cambridge: Harvard, 1994) 80.

34. I won't call it a "willing" suspension because many people don't seem to recognize the contradiction in the first place.

35. "Epic Theatre and Dramatic Theatre," Sartre on Theatre, ed. Michel Contat and Michel Rybalka, trans. Frank Jellinek (New York: Pantheon Books, 1976) 86-7.

36. See Stein Bråten, ed. On Being Moved : From Mirror Neurons to Empathy (Amsterdam: John Benjamins, 2007); and Maxim I. Stamenov and Vittorio Gallese, eds. Mirror Neurons and the Evolution of Brain and Language. (Amsterdam: John Benjamins, 2002).

37. For this debate, see Peter Carruthers and Peter K. Smith, eds. Theories of Theories of Mind. (Cambridge: Cambridge U P, 1996).

38. See Halliwell, Poetics 45-6.

39. Paul Ricoeur, Oneself As Another, trans. Kathleen Blamey (Chicago: U of Chicago P, 1992).

40. This is one reason for Brecht's recognition of the value of what he called Plumpesdenken (or "crude thought") for staged communication. 